Results In total 164 infants were evaluated. Infants with increased placental ischemia and a higher placental maturation score had elevated levels of BNP at birth $\left(\mathrm{r}^{2} 0.12 ; \mathrm{p}<0.001\right)$. Furthermore BNP was found to be associated with (chronic) prenatal hypoxia-ischemia (nucleated red blood cells $\left(\mathrm{r}^{2} 0.22 ; \mathrm{p}<0.001\right)$; intrauterine growth retardation $\left(\mathrm{r}^{2} 0.18 ; \mathrm{p}<0.01\right)$; postnatal thrombocytopenia), and acute perinatal hypoxia (umbilical artery $\mathrm{pH}\left(\mathrm{r}^{2} 0.14 ; \mathrm{p}<0.001\right)$; serum lactate $\left(\mathrm{r}^{2} 0.11 ; \mathrm{p}<0.001\right)$.

Conclusion Elevated BNP levels after birth are found in those preterm infants with significant perinatal hypoxia-ischemia and are possibly related to placental dysfunction. If BNP levels are related to prenatal signs of circulatory compromise needs further investigation.

\section{IMPACT OF OPEN DUCTUS ARTERIOSUS ON CEREBRAL OXYGENATION DURING THE FIRST DAY OF LIFE}

doi:10.1136/archdischild-2012-302724.0789

${ }^{1} \mathrm{C}$ Binder, 'B Urlesberger, ${ }^{2} \mathrm{C}$ Einspieler, 'E Ziehenberger, 'W Müller, 'G Pichler. 'Neonatology; 'Institute of Physiology, Medical University of Graz, Graz, Austria

Background In neonates the ductus arteriosus (DA) plays an important role in hemodynamics and oxygenation. Aim of this study was to analyse influence of an open DA on cerebral tissue oxygenation $\left(\mathrm{CrSO}_{2}\right)$ during the first day of life.

Methods In this prospective observational study nearinfrared-spectroscopy (NIRS) measurements were performed on the right forehead during the first 24 hours of life in preterm and term infants. Cardiac ultrasound was performed immediately after beginning and after cessation of NIRS measurements. Based on the second ultrasound infants were divided into "open DA" and "closed DA" group. Diameter and DA-ratio (time left to right/total shunt time) were assessed in case of open DA.

Results Altogether 28 neonates with gestational age of $35 \pm 3$ weeks and birth weight of $2457 \pm 929 \mathrm{~g}$ were included. Cardiac ultrasounds were performed at $5 \pm 3$ and $24 \pm 5$ hours after birth. All infants had an open DA on the first ultrasound without significant difference between the two groups concerning ductal diameter and DA-ratio.

17 neonates had a closed DA and 11 an open DA on the second ultrasound. Groups did not differ in demographic data.

$\mathrm{CrSO}_{2}$ of closed DA group was significantly higher from 4 to 8 and 10 to 24 hours after birth. Mean $\mathrm{CrSO}_{2}$ of the 24 hours was $80 \%$ in closed DA and $65 \%$ in open DA group.

Conclusion Infants with a closed DA at the end of the first day of life have significantly higher $\mathrm{crSO}_{2}$ during the first 24 hours of life than infants with an open DA.

\section{EFFECT OF PHOTOTHERAPY ON EPISODES OF APNEA AND BRADYCARDIA IN PRETERM INFANTS BREATHING SPONTANEOUSLY}

doi:10.1136/archdischild-2012-302724.0790

S Supcun-Ritzler, W Pielemeier, S Heitmann, C Roll. Department of Neonatology and Paediatric Intensive Care, Vest Children's Hospital, University of Witten-Herdecke, Datteln, Germany

Background and Aims We asked whether rates of apnea and bradycardia increase during phototherapy in preterm infants breathing spontaneously.

Methods Preterm infants ( $\mathrm{n}=60$, median gestational age 29 weeks (range 24-32), birth weight $1205 \mathrm{~g}$ (630-1750), age at study $3 \mathrm{~d}$ (1-10) receiving phototherapy for hyperbilirubinemia (total serum bilirubin $8.5(4.2-16.1) \mathrm{mg} / \mathrm{dl})$ underwent continuous registration of body temperature, heart rate, respiratory rate, arterial oxygen saturation, and transcutaneous (tc) pCO2 for $12 \mathrm{~h}$ ( $3 \mathrm{~h}$ before, $6 \mathrm{~h}$ during, $3 \mathrm{~h}$ after phototherapy). Rates of bradycardia (heart rate
$<80 \mathrm{bpm})$ and oxygen desaturation $(<80 \%)$ were determined for each of the 3 observation periods.

Results Body temperature $\left(37.0 / 37.1 / 37.2^{\circ} \mathrm{C}\right.$; $\left.\mathrm{p}<0.001\right)$ and heart rate $(142 / 149 / 148 \mathrm{bpm} ; \mathrm{p}<0.001)$ increased significantly, while tcpCO2 decreased $(42.5 / 38.0 / 37.0 \mathrm{mmHg} ; \mathrm{p}<0.001)$. Average oxygen saturation and respiratory rate remained unchanged. Rates of bradycardias and desaturations decreased after phototherapy, compared to rates before or during phototherapy $(p<0.001$ for both parameters), and numbers of infants with a least one bradycardia/3h declined (13/10/2).

Conclusions Phototherapy was not associated with increased cardiorespiratory instability. Unexpectedly, episodes of apnea and bradycardia decreased significantly during the first 3 hours after phototherapy.

\section{EFFECTS OF AQUAPHOR ON TRANSEPIDERMAL WATER LOSS AND ELECTROLYTE BALANCE IN PRETERM NEWBORN INFANTS}

doi:10.1136/archdischild-2012-302724.0791

B Chaban, E Ogundipe, SL Chuang, J Maimaris. Neonatal Medicine, Chelsea and Westminster Hospital, Imperial College, London, UK

Background The skin of the preterm infant is immature at birth and unable to serve as an effective epidermal barrier whose major functions and prevention of transepidermal water loss (TEWL).

The Aim of the study is to determine the effect of topical ointment therapy (Aquaphor) in newborn preterm infants on their TEWL measured using total body water (TBW), fluid intake and metabolic balance in the first week of life. Secondary outcomes were all so noted (sepsis, CLD, PDA and IVH).

Methods This is a prospective randomised controlled trial in a single tertiary centre. Twenty six newborn preterm infants $<30$ weeks gestation were randomised into 2 groups; treatment with Aquaphor or a control group. The infants TBW was measured using the Body Stat method as described for neonates by Tang that measured total body water content using bioelectric impedance.

Results There was no statistically significant difference in TBW between the 2 groups from day 4-7 of life. However, the treated group showed an improved trend in their base deficts from day 1 to 7 when compared to controls. This finding supports the hypothesis that metabolic balance in extreme preterm babies may improve with Aquaphor treatment in the first week of life.

Conclusions There was no increase in sepsis or metabolic derangement. Rather, the trend was for better metabolic balance in the treated group from day 1-7 when compared to controls. Larger studies are needed to elucidate the role of Aquaphor in preterm fluid control.

\section{PREDICTORS OF FLUID RESPONSE IN A ANIMAL MODEL OF HEMORRHAGIC SHOCK}

doi:10.1136/archdischild-2012-302724.0792

1J Urbano, 1,2R González, 1,2MJ Solana, 1,3J López, 'M Botrán, 'A García, 1,3J LópezHerce. 'Paediatric Intensive Care Unit, Gregorio Marañón General University Hospital and Research Institute; ${ }^{2}$ Healthcare Research Fund; ${ }^{3}$ Maternal and Child Health and Development Research Network, Carlos III Healthcare Institute, Madrid, Spain

Background and Aims Prediction of fluid response is of paramount importance when managing shock. The aim of the present study was to test the hypothesis that pre-infusion values of several hemodynamic and perfusion parameters could help to predict fluid responsiveness in an infant animal model of hemorrhagic shock.

Methods Prospective, observational study in 20 two month-old piglets $(9.9 \pm 2 \mathrm{~kg})$. Following mechanical ventilation, hypovolemia was induced by controlled $30 \mathrm{ml} / \mathrm{kg}$ bleed. After $30^{\prime}$ pigs received Normal Saline (NS) $30 \mathrm{ml} / \mathrm{kg}, \mathrm{n}=10$ or Albumin $5 \%$ plus Hypertonic 